\title{
What do the humanities (really) know about doping? Questions, answers and cross-disciplinary strategies
}

\author{
Ask Vest Christiansen $^{\mathrm{a}, *}$, John Gleaves ${ }^{\mathrm{b}}$ \\ a Section for Sport Science, Department of Public Health, Aarhus University, Dalgas Avenue 4, 8000 Aarhus C, Denmark \\ ${ }^{\mathrm{b}}$ Kinesiology and Health Science, California, State University, Fullerton, 800 North State College Boulevard, Fullerton, CA 92834, USA
}

\section{A R T I C L E I N F O}

\section{Article history:}

Received 20 February 2014

Received in revised form 10 June 2014

Accepted 13 June 2014

Available online 26 July 2014

\section{Keywords:}

Doping

Research

Humanities

Scientism

Social constructivism

Cross-disciplinary

\begin{abstract}
A B S T R A C T
Recent years have brought debates about the future role of humanities research in light of sciences' progress. In doping research, tacit biases in favour of science risk ignoring the humanities in their efforts to understand and address the doping phenomenon. This article is a continuation of the discussion on the role of the humanities and social sciences in research on drug use in sport. The article asserts that until those who wish to address the doping issues in sport begin engaging humanities and social science research alongside the natural sciences, the results from scientific experiments will remain detached from the lived experiences of the athletes, and the anti-doping campaign risks losing its legitimacy. Conversely, we will also argue against two types of drawbacks for humanistic research; one is the dismissal of the pursuit of truth in exchange of epistemological relativism. The other is the tendency to turn inward and become reluctant to use empirical tools that provide purchase on the doping issue. The article will conclude by sketching a positive account of the two fields collaborating with more porous borders but one that asks neither side to compromise its professional standards or modes of inquiry. This new account asserts that future doping research requires cross-disciplinary and collaborative research rooted in strong methodologies but conversant in both languages.
\end{abstract}

(C) 2014 Elsevier Ltd. All rights reserved.

\section{Introduction}

What do the humanities really know about doping? Without doubt, humanities-based scholars have produced a great quantity of research - both quantitative and qualitative, empirical and nonempirical - on this topic. ${ }^{1}$ Yet what has such work amounted to? Critics of the humanities could point to a seemingly endless debate over legalising doping or the reproduction of doping myths in history, as evidence that the humanities have produced very little. In part, critics contend, the humanities lack the necessary methodological rigour and do not contribute anything of practical value from their largely theoretical world. The natural sciences, such critics continue, are both methodologically sound and grounded in the objective 'real world' - one free from 'flighty theories' and 'fashionable arguments'. Sure social scientists can cast doubt onto the

\footnotetext{
* Corresponding author. Tel.: +45 27782833.

E-mail address: avc@sport.au.dk (A.V.Christiansen).

1 By humanities, we mean research focused on human culture and society. This includes research in traditionally recognised humanities disciplines as well as certain social science disciplines, specifically: history, philosophy, communication, ancient and modern languages, literature, religion, and visual and performing arts, anthropology, sociology, cultural studies, and law.
}

empirical value of scientists' ability to detect a given drug with a sensitivity of X (Pitsch, 2011) or that less than one in one thousand athletes tested positive during the 2012 London Games (WADA, 2012). After all, no athletes tested positive at the 1980 Moscow Olympics (Todd \& Todd, 2001) and neither did Lance Armstrong during his reign in cycling, and myths have also been reproduced in the natural sciences. But such events may be explained away by poor on-site testing protocols, lack of funding for developing appropriate tests or corruption of various individuals or organisations. Also, the science camp may point to the larger failures of humanities-based researchers such as those in history, sociology, law, and ethics, who have produced theories but no meaningful solutions to the doping issue, and could thus be accused for lacking the same "vibrancy, sophistication and maturity" as the medical and physical sciences have developed (Mazanov, 2009).

To be sure, this science vs. humanities debate is larger than the issue of doping (Snow, 1993). However, it is not just a relic of the mid twentieth century science wars, but noticeably applicable to the doping issue of today since, as we will argue, the field so clearly draws on both types of scholarship yet often privileges the hard sciences. This article is thus a continuation of the discussion on the role of the humanities and social sciences in research on drug use in sport (e.g. Gleaves, 2011; Mazanov, 2009; Møller, 2006). 
The argument here is that there is a tendency for policy makers and scientists to ignore the humanities in their efforts to understand and address the doping phenomenon. This state of affairs is troubling for all sides. If stakeholders wish to seriously address doping in sport, it is necessary to incorporate humanities and social science research when developing new policies and strategies. Otherwise the results from laboratories will remain out of touch with the experiences and issues athletes face and the anti-doping campaign risk losing its legitimacy. Conversely, unless humanities researchers recognise that their work draws upon and should contribute to disciplines beyond their own silos, their work will not be taken seriously by those charged with conducting scientific research or implementing policy.

But there is a road map forward. Based on past influential research, we will argue that not only is a one dimensional reliance on science epistemologically unfounded but the tendency for scientists to address ethical and cultural questions shows scant appreciation for the complexities of the issue unearthed by scholars in the humanities. At the same time, we will also argue that some branches within the humanities have turned inward and remained somewhat reluctant to use empirical tools that provide purchase on the doping issue. Others have advanced their empirical findings along with a distrust of "truth-with-a-capital-T," and instead suggested a variety of perspectives and 'truths' of which no one can claim superiority.

With such approaches it has been too easy for scientifically minded scholars to set aside the work of their humanities-based colleagues. Since a "two-state solution" between the humanities and the sciences helps no one, we will last attempt to sketch a positive account with more porous borders but one that asks neither side to compromise its professional standards or modes of inquiry. We will conclude that future doping research requires cross-disciplinary and collaborative research rooted in strong methodologies but conversant in both languages.

\section{Scientism and the culture of science}

While few, if any, really think that science will replace the humanities, the perception that the humanities now serve as the handmaiden to the sciences and that real progress will emerge from scientific inquiries dominates the applied world of performanceenhancing drugs and sports. Such a view is often ascribed the label 'scientism' - the belief that the natural sciences constitutes the most authoritative view and that the scientific method is the ideal methodological approach to research as such. Most scholars acknowledge that scientism is a caricature useful for illustrating tacit preferences for scientific methods rather than an endorsed worldview. Still, philosophers of science note the strong tendency for scientism to influence preferences for data and investigations of the natural world (Putnam, 1992). In an interview featured in The Atlantic the highly recognised theoretical physicist Lawrence Krauss commented on the tension between groups of philosophers and natural scientists by saying that: "people in philosophy feel threatened, and they have every right to feel threatened, because science progresses and philosophy doesn't." In fact, Krauss was quoted for saying that philosophy "hasn't progressed in two thousand years" (Andersen, 2014). In doping research, the tendency for scientism to creep in also comes with a second effect: some scientists believe their 'authoritative view' from the natural sciences translates into equally authoritative claims more properly suited to the humanities. These cases of "scientists doing humanities" illustrate how unstated preferences for the sciences play out in doping research.

One example of such cases is the drug epidemiologists Yesalis and Bahrke's article "Doping Among Adolescent Athletes" (2000).
Yesalis and Bahrke begin their article, published in an Endocrinology journal, with the dubious claim that "The use of drugs to enhance physical performance and appearance has been observed for thousands of years," and conclude with an extended ethical conversation that focuses on the need to "reform social values." Historians such as Hoberman (1992) and Dimeo (2007) note that broad generalisations linking doping to sporting practices of past millennia ignore not only important contextual points about modern sport but also lack supporting evidence. The latter axiological claims illustrate the common habit of scientists using empirical data to make humanistic claims while ignoring the relevant literature already produced by the humanities. Claims such as Yesalis and Bahrke's "Ours is a culture that thrives on competition - both in business and in sport," (2000, p. 31) or "Philosophically, many in our society appear to have taken a 'bottom-line' attitude and consider winning to be the only truly worthwhile goal of competition," (2000, p. 31) do not use appropriate evidence to justify or substantiate their philosophical, cultural, and historical assertions. Such claims cannot be defended on the empirical evidence the authors present in the article nor does the conclusion necessarily follow from their premises. Absent supporting evidence, such broad claims about human nature and the state of modern culture reflect the hubris of scientism. The example is not meant as critique of science as such, since most scientists would recognise that neither authors are doing science with their claims; rather, the example illustrates the authors' tacit scientism at work.

Others have chosen to reinterpret historical behaviours through contemporary lenses. In their work on erythropoietin published in the journal Sports Medicine, Diamanti-Kandarakis et al. cite a passage from the Greek epic The Illiad where Odysseus prays for help from the god Athena as "likely the oldest documentation of an athlete winning a competition with a "little help from his friends"' (2005, p. 831). While tongue-in-cheek, such historical reinterpretations of human behaviour and doping allow authors such as Diamanti-Kandarakis et al. to infer claims about human nature that lead to conclusions about inherent drug use and "athletes determined to win at all costs" (2005, pp. 831-832).

Along these lines, one of the most repeated claims is that athletes are willing to die for a medal. This claim holds that the athlete's mentality is somehow completely out of line with other human beings', so that they are willing to swallow or inject whatever it takes regardless of the consequences. As evidence, scholars often refer to a more than thirty five year old survey by Gabe Mirkin. Mirkin claims that the he made a survey among "more than a hundred top runners", whom he asked: "If I could give you a pill that would make you an Olympic Champion - and also kill you in a year - would [you] take it?". Mirkin subsequently states: "To my amazement, more than half of the athletes responding stated that they would take my magic pill" (Mirkin \& Hoffman, 1978, p. 84). But that is all the information that exists. The authors provide no methods, no design, no details, and no references in their text. But it has apparently been sufficient for many scholars to pass on the assertion as firm evidence of elite athletes' extraordinary psychologically constitution. Bob Goldman repeated the survey several times with largely the same result. But like Mirkin he does not give any detailed information on design and method of his study. Just the fantastic result (Goldman, Bush, \& Klatz, 1984, p. 34). In both cases, the claim about athletes' unusual psychological constitution, including the inferences about how elite sport environments creates cultures where such mind-sets develop, were forwarded in physiology oriented books, by authors with a sports medicine background. Disregarding the problem of the surveys, that would exclude the results from publication in any scientific journal if they were presented as new findings today, the conclusion - that athletes are willing to die for a medal - is often repeated in the literature on drugs in sport (e.g. Carroll, 2005; Gleason \& Barnum, 1994; 
Neuberger, Jurkiewicz, Moser, \& Simon, 2012; Todd, 1987; Wilson, Gilbert, \& Edwards, 2004). This is not least discouraging since the only study that have tried to replicate the Mirkin/Goldman survey in a scientific manner has found the complete opposite conclusion: very few athletes are willing to die for a medal. Indeed, athletes' psychological constitution is in this respect similar to that found in the general population (Connor \& Mazanov, 2009; Connor, Woolf, \& Mazanov, 2013). Although without the requisite methodology, the findings of Mirkin/Goldman are apparently too good not to be mentioned. And at the same time, have worked to support calls for firmer anti-doping legislation (e.g. British Medical Association, 2002; Greydanus \& Patel, 2010).

The media scholar Bernat Lopez has also shown how cultural perceptions of doping shaped scientific research. Lopez argued that Randy Eichner's reports on blood doping are filled with unsubstantiated historical claims ranging from the origins of blood doping to the (now refuted) myth of 20 deaths among professional cyclists following the introduction of recombinant erythropoietin in the 1990s (Eichner, 2007; López, 2011). By putting such claims in print, Eichner eschews scholarly standards - standards equally held by the sciences and the humanities - that demand researched evidence and citations to support the veracity of claims.

Recently, another dominant myth was reproduced by PierreEdouard Sottas, the WADA manager of the Athlete Biological Passport, at a research seminar titled "DOPING - Effects, Side Effects and Detectability", hosted by Anti-Doping Denmark in November 2013. In his presentation entitled "The Steroid Module: The Development of Steroid Profiles" Sottas claimed that German troops used anabolic steroids during World War II. This connection juxtaposed a phenomenon (steroids) with a recognised evil (Nazis) whereby the evil of the former can be inferred. ${ }^{2}$ Although widespread in the literature the story is myth. It has been shown with reliable evidence that German troops never used anabolic steroids (Reinhold \& Hoberman, 2014). But, again, the reproduction of such myths can be used to influence policy.

In fact, such tacit scientism can lend scientists authority when influencing policy, even on traditionally humanistic claims. For example, in a 1985 article by Harvey Klein, a medical doctor with the United States' National Institutes of Health, Klein condemned the 1984 U.S. cycling team's use of blood transfusions at the Los Angeles Olympic Games (Klein, 1985). Though not prohibited by the rules, Klein argued that the practice was unethical and "provides athletes with an unfair competitive advantage" (Klein, 1985, p. 856). How it is unfair when it is not prohibited is left unclear, but Klein's work would inform the report given by Don Catlin, another medical doctor, to the International Olympic Committee later that same year (Catlin, 1986). It would be on the basis of this report, one laden with ethical judgements that far outpace a medical doctor's expertise, that the IOC would rewrite its policies not only on blood doping but also how it approach to anti-doping rules.

Similarly, the recognised blood doping expert Michael Ashenden waded into the policy debate in 2007 when he suggested a radical solution for surveillance of elite athletes. Ashenden's idea was that athletes should be equipped with a GPS-device (for instance on their wrist, around their ankle or inserted under their skin), so that anti-doping officials could track and find them for testing at all times (Evald, 2009). ${ }^{3}$ Despite the obvious ethical and

\footnotetext{
2 Which bears some reference to Godwin's Law that says that: "As an online discussion grows longer, the probability of a comparison involving Nazis or Hitler approaches 1." See: http://en.wikipedia.org/wiki/Godwin\%27s_law Accessed 06.06.14.

3 The idea was presented at the Play the Game conference in Reykjavik, Iceland, in 2007, in a presentation entitled: "Blood testing: Pushing the envelope". See: http:// www.playthegame.org/conferences/play-the-game-2007/presentations.html Accessed 06.05.14
}

legal objections to such intervention, Ashenden argued in favour of this step citing the nature of athletes and the amount of new products constantly available from the pharmaceutical industry. This inference, and the conclusion he reached, go beyond Ashenden's expertise in human physiology while ignoring ethical and legal scholarship on rights to privacy, autonomy, and human dignity.

Certainly playing loose with history, ethics, and claims about human nature does not equate to a blind faith that science can solve all problems. It does, however, reveal the tacit biases towards the humanities that are symptomatic of scientism. Such claims show that not only the authors, but also the editors and the scientific community consider humanistic claims worthy of less scrutiny than those offered to scientific data collection. This does not mean that any field is above reproach for reproducing myths; rather, it is that scientific claims are taken more seriously than their humanistic equivalents and that when sciences report humanistic claims, they are given more authority despite dubious evidence. Allowing such claims, however innocuous, into peer-reviewed literature tacitly endorses them without requesting the necessary evidence. As scholars cite previous works and reproduce conclusions, these claims take on an air of truth. Such a state turns scholarship into a house of cards, as the unravelling of one false premise risk bringing down a cascade of others with it - both for the natural sciences and the humanities. It can also make correcting false assumptions difficult as accepted though disproven claims seem to spring up like weeds in the garden of academic literature - the myths on Nazisteroids, Mirkin's claim about athletes' willingness to risk their lives for a medal, and EPO causing the death of 20 Dutch and Belgian cyclists are prime examples hereof (for refutations of these myths see Christiansen \& Møller, 2007; López, 2011; Reinhold \& Hoberman, 2014).

Humanistic scholars learned the lesson of such disciplinary hubris all too well when physicist Alan Sokal famously played a hoax on literary critics in 1996. His essay, "Transgressing the Boundaries: Towards a Transformative Hermeneutics of Quantum Gravity," appeared in the highly regarded journal Social Text and was intentionally filled with scientific inaccuracies and nonsense claims but designed to match the editorial staff's ideological biases (Sokal, 1996). Having permitted the article to go forward unchallenged, the larger academic community questioned the editors' own intellectual rigour as well as their postmodern positions. The Sokal hoax revealed numerous lessons, one of which might be that the humanities scholars cannot simultaneously write about and take over concepts from the natural sciences and lack a basic understanding of what they have offered.

If we consider the issue from the other direction (scientists making humanities claims), we see the risks. Scientists making ethical conclusions based on their empirical findings risk speaking about something their training has not prepared them to speak accurately about. Moreover, they risk committing a fundamental fallacy. This fallacy is moving from statements of natural facts to statements about moral norms. Known to philosophers as "Hume's Law," or the naturalistic fallacy, the reasoning goes that claims that involved the propositions "is" and "is not" cannot logically lead to propositions that involved "ought" and "ought not." The reason is that, "ought, or ought not, expresses a new relation or affirmation," and that it seems inconceivable "how this new relation can be a deduction from others, which are entirely different from it." However, scientists, whose realm of natural facts lends themselves to studying the "is" properties, should note Hume's point that "the distinction of vice and virtue is not founded merely on the relations of objects [emphasis added]" (2003, p. 335). For example, the claim by Lundby and Olsen that "in normal subjects both long-term administration of low doses of EPO and short-term bouts of high-dose EPO may produce arterial hypertension," indicates that there might be a health risk associated with the use of EPO (Lundby \& Olsen, 2011, 
p. 1267). What is unclear is how scientists and medical doctors (but, to their credit, not Lundby and Olsen) can move from basic claims about physiological effects to moral claims about the ethics of using doping to enhance performance. For example, at a conference on "Doping and the Press," held in Copenhagen in October 1998, exercise physiologist, professor Michael Kjær, rejected the legalization of doping on two grounds: one was "that it contained an element of cheating", the other "that doping is unhealthy" (Møller, 2008, p. 29). The fact that legalising doping would eliminate his first argument, and that his second argument not only violated Hume's law, but also that accepting it at face value would require the banning of a lot of other things (not least in an era where obesity is said to have reached epidemic heights), was apparently less important than condemning a practice everyone by default know is wrong.

Thus, even if everyone agrees that doping or EPO is unhealthy, a normative claim does not logically follow from this factual claim. The natural fact of a substance's health effects does not tell the sporting world what to do. When advising stakeholders as though "ought" followed from "is," scientists venture beyond their realm of investigating the natural world and into ethical claims about how people should behave. In line with this, scholars such as Møller (2010), Kayser, Mauron, and Miah (2007) and Miah, Kayser, and Mauron (2005) have pointed out, many aspects of sport are unhealthy but not equally prohibited. Although these authors illustrate inconsistencies in the focus on doping, their point that health is not universally recognised as cause for ban shows that "health" requires ethical interpretations.

Regarding policy, hints of scientism also emerge with the World Anti-Doping Agency (WADA). For example, WADA frequently expresses their desire to use scientific knowledge and data-driven evidence in its fight against doping. WADA reports to have spent USD56 million on scientific research on anti-doping, including detection, identification, and pharmacology. Moreover, its Strategic Plan cites the desire to

Implement an international scientific research program and foster an international scientific research environment and expert network that monitors and predicts trends in doping science and actively promotes reliable research outcomes in the effective development, improvement and implementation of detection methods (WADA, 2011, p. 5).

Conversely, their Strategic Plan makes no mention of any effort to improve the ethical, historical, cultural, or political research on doping. This plays to the tacit assumption that doping research in the humanities and the "softer" social sciences has little applicable value. This omission is puzzling considering how ex-WADA president Dick Pound explains that:

The primary reason for the apparent lack of success of the testing programs does not lie with the science involved. While there may well be some drugs or combinations of drugs and methods of which the anti-doping community is unaware, the science now available is both robust and reliable. The real problems are the human and political factors" (Pound, Ayotte, Parkinson, Pengilly, \& Ryan, 2013, p. 3).

Pound's recognition of the problems of "the human and political factors" in doping ironically plays out in WADA's application of "the spirit of sport". While the concept's ambiguities is supported by some sport ethicists (with reference to Wittgenstein's notion of fuzzy pictures) as necessary and positive (McNamee, 2012), the inconsistency and the impossibility of applying it in a meaningful and universal manner has been demonstrated by other scholars (e.g. Mazanov \& Connor, 2010; Møller, 2010; Tamburrini, 2006; Waddington \& Smith, 2009; Waddington, Christiansen, Gleaves, Hoberman, \& Møller, 2013). To accept, however, that the concept is not universally applicable to elite sport would entail that WADA granted the criticism raised by many humanities scholars. Such acceptance, however, would risk shaking the foundation of WADA's whole enterprise. This might be a reason why WADA, as part of its organisational practice, favours natural science research rather than social science and humanities research in its Strategic Plan. At least, when looking at the social science WADA has funded, ${ }^{4}$ it is easy to get the impression that projects that risk jeopardising the cornerstones of the anti-doping campaign are left out.

While we do not attempt to buy into the rhetorical strategy of using the concept of scientism as a boo-word against colleagues in the scientific field, a tendency thus exists to dismiss those in the research community who do not pursue a scientific approach, while at the same time accepting humanistic or social science claims by natural scientists. Even the more conservative approach that acknowledges that science cannot resolve all of the ethical, legal, health-related and social questions still hold that it is likely the only real path to resolving "real world" issues like curing diabetes, improving the economy or stopping doping. In the case of the latter, scientism pulls resources towards improved detection methods, innovative biomarkers, or better laboratory facilities rather than the host of cultural, social, or ethical issues that persist. This ignores the cultural dimensions of the doping phenomenon. However, the partiality towards the natural sciences is not solely the fault of scientism. In fact the humanities may also have played a role in their own relegation.

\section{The unreliability of humanities in doping}

When scholars want to know why athletes choose to dope, or want to know about doping cultures, or about the normative reasons not to dope, they cannot always calculate or test samples in the same manner as can be done in science. Here, the methods of the humanities are employed; which analyse cases, conduct observations and interviews, and rely on reason, logic, and personal experience. Humanities scholars have used these tools from a variety of disciplines over the last decade to better understand the doping phenomenon (Beamish \& Ritchie, 2006; Brissonneau \& Ohl, 2010; Christiansen \& Møller, 2007; Christiansen, 2005; Dimeo, 2007; Fincoeur, 2010; Hardie, Shilbury, Ware, \& Bozzi, 2010; Møller, 2008; Waddington \& Smith, 2009).

However, although the humanities can utilise a number of different methodologies some basic, indispensable standards need to be met. First, we need to have truth as an ideal for what we say in our work. Even if we acknowledge, as fallibilists like Popper (1992), that we might not ever be certain that we have arrived at truth, we can revise our conclusions to work towards the ideal of truth. Second, when acknowledging that many concepts and phenomena are socially constructed, we must take care as to how far we wish to extend this insight. Problems arise when, for instance, historian Douglas Booth cites Hayden White's conclusion that historical evidence "can be put together in a number of different and equally plausible narrative accounts" and that these choices, Booth adds, "carry distinct ideological and political implications" (2005, p. 12). Citing a quote from historian Dan Nathan, Booth asserts that "irrespective of our sources and evidence, 'we tend to see what we want to see, believe what we want to believe"' $(2005$, p. 81$)$. If such claims are true, that history can be written in many ways and based on our own subjective views, then it becomes difficult to differentiate history from fiction or propaganda. And if that is true, what value can it have when compared against the rigorous objectivity of science? With so much doubt about the humanities, one could easily become

\footnotetext{
${ }^{4}$ See http://www.wada-ama.org/en/Education-Awareness/Social-Science/
} Funded-Research-Projects/ for a list of social science projects funded by WADA. 
a sceptic or a cynic about their validity as fields and ask what their validity is if they have no purchase on truth?

Such claims lead to accusations that the humanities are just words without positive knowledge. This is in contrast to the natural science where knowledge is put forward on the grounds of statistical probability. Science uses probability statements to illustrate its admission that they cannot provide certainty beyond some degree of statistical doubt. The humanities, on the other hand, often derive empirical data from observations, interviews or case studies and then try to establish analytical generalisations. But too often a scholar (while presenting her conclusion) states that she certainly does not believe in truth with a capital T. In this light, it is understandable why the humanities sometimes meet resistance or - even worse - are not taken serious by either the public or the natural sciences. Yet this lack of respect should be considered an inside job. Postmodernist, poststructuralist, feminist, social constructivist and likeminded scholars have argued that not only phenomena like games, taboos, social practice or the concept of doping are social constructions (which they undeniably are), but go farther to assert that fundamental entities such as language, knowledge and truth are also social constructions (for an elaborated discussion on how and why these groups of academics do so, see for instance Benson \& Stangroom, 2006; Favrholdt, 1999; Pinker, 2002; Widell, 2004). The thinking is that if social constructivism ${ }^{5}$ works well on analysing games, taboos, social practice and the like, then it must also work when analysing the warranted findings of knowledge and scientific research. If social practice is based on and caused by social factors, interests and agendas then that also go for scientific knowledge since this is also generated in a social setting. Truth, in this perspective, thus becomes a social construction. To argue against the social constructivist position in favour of a realist position is not equivalent to claiming that one knows the truth or has found it. On the contrary, scholars with a realist position acknowledge or, as Benson and Stangroom puts it, "they insist" that

knowledge is always provisional, always subject to revision if better evidence is discovered, and most of them have no quarrel with the thought that social factors and extraneous agendas can shape priorities, lines of inquiry, funding, education, and the like (Benson \& Stangroom, 2006, p. 65).

Hence a continuous will to doubt the validity of the knowledge generated is a core element of the realist position. But at the same time the endeavour is all about getting closer to truth. Truth is an ideal one must pursue. The problem with the relativist position held by social constructivists is that the doubt is taken too far; social interests, ideology, gender, race and power relations become the explanation for all knowledge and scientific results. Epistemic interest shrinks into void. Examples of this line of thinking in humanistic and social science research on sport issues can be found in the works of for instance Ryba and Wright (2010), Hall (1996) and Magdalinski (2009). On their take to the knowledge accumulated in sport psychology Ryba and Wright for instance states that their

\footnotetext{
${ }^{5}$ We are aware that some scholars make a distinction between "social constructivism" and "social constructionism". We have chosen the notion social constructivism for this paper. Social constructivism and social constructionism are two parallel versions of constructivism, which - departing from Berger and Luckmann's the Social Construction of Reality (1964) - assert that our social world is socially constructed. The suffixes -vism and -nism are markers of professional academic affiliations but it is hard to make clear distinctions between the two -isms. The notion social constructivism is often preferred by social science researchers. On the other hand the notion social constructionism is mostly used in the international (social) psychological and humanistic literature. Both paradigms are critical towards established science and research and rejects so-called positivistic, empirical research. Instead they lean towards qualitative methods and are philosophically often strongly inspired by Nietzsche, Foucault and Derrida (Larsen and Pedersen, 2011).
}

constructivist approach is meant to counter "the hegemonic white (and often male, heterosexual) way of knowing by virtue of 'othering."' Their own method "rejects taking up knowledge as neutral and an end in itself", while it involves a "reexamination of ontological, epistemological, analytical and political underpinnings" of their field. Their tools are thus applied to "examine ideological, moral and ethical implications of the western power-knowledge" (Ryba \& Wright, 2010, pp. 6 and 10). Likewise in their collection on Gender/Body/Knowledge - Feminist reconstructions of being and knowing the editors in the Introduction state that the unity of the articles in the volume "consist of an emerging feminist challenge to conceptions of knowledge and reality that have dominated the western intellectual tradition at least since the seventeenth century." This challenge is needed, the editors argue, since the realist "framework is fundamentally inadequate, an obsolete and self-deluded world view badly in need of reconstruction and revisioning" (Jaggar \& Bordo, 1992, pp. 2 and 4).

As demonstrated by a number of scholars from a variety of disciplines, such constructionist thinking is not only epistemologically unsound but also undermines the reliability of humanistic research (Benson \& Stangroom, 2006; Favrholdt, 1999; Konner, 2002; Pinker, 2002; Tooby \& Cosmides, 1995; Widell, 2004). Such scholars have noted several problems with their constructivist colleagues' positions. First and foremost, one might ask "If what I say, is only true for me and my perspective, and cannot be generalised to a broader population, why should anybody then take my statements serious? And why should I bother to share my knowledge to anyone, in the first place, if I believed that it was only valid for the specific instance, perspective or case that I studied?" To be fair, scholars that take such positions seldom claim that their findings are only relevant in the specific context in which they were found. That is, they do not themselves believe the inferred prepositions from the epistemological claims they put forward in their works (see e.g. Gergen, 2000). Danish doping scholar Verner Møller points out that if they really believed that no fundamental difference existed between, for instance, historical and fictional texts (as Douglas Booth hinted above), there would be no reason to go through all the troubles of substantiating claims with quotes and references. In that sense, Møller states, there is, "a remarkable discrepancy [...] between form and content" in these scholars' work (Møller, 2006, p. 454).

A subtle version of a relativist approach is to apply a Wittgensteinian framework to one's research. It is often addressed (and celebrated) as "the linguistic turn" in the humanities and social sciences, and with reference to Wittgenstein it holds that words and concepts cannot be understood outside the realm of the life world in which they were uttered. In order to illustrate this scholars have often pointed to Wittgenstein's discussion on how the word "game" is used and concludes "if you look at them you will not see something that is common to all, but similarities, relationships, and a whole series of them at that" (Wittgenstein, 1996, §66).Wittgenstein's point is that the myriad of comprehensible uses to which the word "game" might be put, reflects the fact that the word has no essence. The meaning is in its use and the different uses of the word are only loosely related to each other. This openness, he noted, did not hinder our use of those words or concepts. For thinkers inclined towards relativism Wittgenstein loans philosophical credibility to the idea that concepts are bound to their context and hence no universal claims about the architecture of the world should have validity. ${ }^{6}$ Wittgenstein's theory of language has thus been a pivotal point in many social constructivist assumptions

\footnotetext{
6 This claim has for instance has been forwarded by the anthropologists Edward Sapir and Benjamin Lee Whorf. It is known as the Sapir-Whorf hypothesis which briefly put states that understandings of the world are constructed through and thus dependent on the ways in which we see the world which again is limited by loca
} 
about language, knowledge and truth. Wittgenstein scholars may argue that this is a misinterpretation, but as British philosophers of science Benson and Stangroom points out:

even if Wittgenstein's ideas are being misapplied [by social constructivists], it is not clear that he would have good grounds for complaint, because, after all, it is only a small step from arguing that words gain their meaning through their use to the claim that so do philosophical theories (Benson \& Stangroom, 2006, p. 36).

Yet instead of seeing the linguistic turn as the most important step forward in the humanities in the last century (Ryba \& Wright, 2010), humanities scholars must consider a realist approach to language, words, and knowledge along with an understanding of human nature in order to demonstrate the continued relevance of the humanities and social sciences to phenomenon like doping. Such a change is needed because social constructivism struggles to go beyond the context of their own research and onto generalisations with implications beyond the local.

Briefly put, the two major faults of social constructivism that has proved detrimental to the overall reliability of humanistic research are (1) the rejection of the concept of truth, and (2) the rejection of the existence of a shared human nature, which is connected to the conception of culture as a sui generis phenomenon.

First, critics of a universal concept of truth argue that no one can claim ownership to truth, and that there are many forms of logic and reason. Just look at the enormous variety of cultures and life forms around the world. But truth is an all or nothing proposition. There is no intermediate position. It is intimately related to concepts such as consistency, logic, thoroughness, universal applicability and the like. If one decides that truth does not matter in one area what is it to prevent one from deciding it does not matter in any area? As Benson and Stangroom states:

The norms of truth have to apply here as well as there if they are to apply at all. That is why relativism about truth is always self-undermining. If we say 'there is no truth, truth is an illusion, a myth, a construct, a mystification', then that statement is not true - so there is truth then. If we say 'your truth is as true as mine' then you can say 'my truth is that your truth is not true' and round we go." (Benson \& Stangroom, 2006, p. 17).

Second, as regards culture, social constructivism claims that social facts can only be explained by social facts - culture can only be explained by culture, and human behaviour can (and should) be explained in purely cultural terms. Human nature does not play any significant role in this. For example, Margaret Mead's influential writings from Samoa (where she had the explicit aim of confuting biological explanations of human behaviour) as well as the founders of American anthropology from Franz Boas and Alfred Kroeber to George Murdock and Robert Lowie all illustrate this perception. According to Lowie psychology could explain just as much about culture, as gravity could explain about the various architectural styles, and in line with Emile Durkheim he stated that culture is a sui generis phenomenon that only can be explained by itself (Konner, 2002; Tooby \& Cosmides, 1995). Culture, in this perception, is something "out there" that is "forced upon us", so to speak. In all instances, the causal arrow goes from the environment to the individual. Thus, from the point of view of social constructivism, human's psychology, or human's shared nature, is not only not to be considered, but purely rejected when investigating the development or constitution of a certain culture. Indeed, social constructivism rejects the idea of a common human nature

languages (Widell, 2004, p. 10). For a closer examination on why Wittgenstein's thesis on family resemblance may be wrong see (Møller, 2012, p. 172 ff.). encompassing a common human psychology that influences how cultures develop and how norms and values are shaped in these cultures.

The reverse position is that there is a commonality, a shared human nature, which is not socially constructed but has developed over the course of evolution and highly influences the construction of cultures. This means that we as people share a number of common traits in our way of categorising, understanding and making sense of the world. Evolutionary psychology has over the last 30-40 years for instance shown how there are substantial common traits in the way we relate to other people, the way we make social rules, in the relations between the two sexes and between members of the same sex (Konner, 2002; Pinker, 2002). The argument is that these commonalities cannot have emerged by chance, since such random probability is highly unlikely. Rather, as these authors argue, the commonalities must be ascribed to a shared human nature - the belief that humans organise and experience the world and relate to others in essentially similar ways across time and culture.

To scholars in the humanities and social sciences, these common traits should not be refuted nor regarded as a problem. On the contrary, it is the salvation of the humanities. It is due to these common traits that humans can intuitively understand the other and they are also the reason why we can analytically extrapolate and generalise from our observations, interviews and cases. Without the existence of a shared human nature and without the possibility of validating our results with $p$-values of less than 0.05 , we would have very few possibilities of saying something truthful and useful about the world. This does not mean that scholars must forget about individuals and only consider larger populations in their research. Quite the reverse; taking our point of departure in the individual and reflecting upon that individual's story, attitudes and thoughts in light of our intuitions of human nature may pave the way for a better understanding of the phenomena under investigation. The philosophy of the Danish author Søren Kierkegaard can help illustrate the case.

\section{The case of Kierkegaard's writings}

In his critique of Hegel, Kierkegaard drew attention to the subject, the individual. For Kierkegaard, the individual is the highest moral entity. Due to the transcendent value of moral considerations, the fundamental human activity is decision making. Kierkegaard concluded that it is through the choices and decisions we make that we create our lives and thus become ourselves. But even if Kierkegaard rejected the Absolute from Hegel's philosophy and instead drew attention to the personal, he is not arguing that we can only speak about that individual person and not generalise. Rather, Kierkegaard's point is that we need to understand that individual first in order to generalise to the many (and that generalisation, we would say today, has a common human nature as it necessary condition). His writings on love are illustrative hereof. In perhaps one of literature's greatest romances, Kierkegaard became engaged to Regine Olsen in 1841. After a short while he started having quarrels over the relationship. Would he make her happy? Was it appropriate to let her into his and his family's deep secrets? Would she understand? Kierkegaard decided to break the relationship only a year later and this had profound implications for his subsequent production (see for instance Kierkegaard 1983 (org 1843); Kierkegaard 1991 (org. 1845)).

So as regards the question of "love" Kierkegaard had a data set where $N=1$, and a personal experience with a relationship of approximately one year. This raises a mystery: How could he with such poor empirical evidence (just one case and he is even subjectively involved), write about love, psychology and morality in a way so that people in China, who read his text more than 150 years 
after they were written, feel that he is writing directly to them? Although it cannot be logically inferred, the most likely answer is that he has tapped into a shared human experience that transcends both time and place. And it is because he wrote his texts with an intuitive insight in this nature that they can resonate with the experiences of people on the other side of the planet 150 years later.

Critics may object, suggesting that we contradict ourselves here since we previously criticised scientists for making "broad claims about human nature." The point here differs, however, since our claim is of an epistemological and not an empirical nature. The quoted scientists making generalisations about human nature did not do so by following their own methodologies. Here, Kierkegaard uses inquiry and questioning - a form of universal hermeneutics - to arrive at insights that others realise as a depiction of human nature. We would also fault Kierkegaard had he used an $N=1$ to arrive at biological claims. That, of course, does not entail that any specific analytical generalisation is true (and it was specific generalisations we criticised), only that it is a logical possibility that it could be so. If one negates the idea of a common human nature, then one also negates the logical possibility that such generalisations could be true.

Cases, interviews and observations can thus be used to form analytical generalisations as long as they are understood in relation to a common human nature. This is not new; the idea of a common human nature is the tacit premise behind hermeneutics a principal form of humanistic inquiry. If one rejects the notion of a common human nature, and instead argues that the human being is a social construction, then one is precluded from using cases and interviews to make inferences. The position could not explain or understand the actions and viewpoints they represent in a more general manner. On the other hand, if we, as an example, want to understand the culture of doping through interviews with elite cyclists, then it is only superficially about each individual cyclist's view on that culture. Ultimately, we conduct the interviews to find the truth about that culture in cycling (at that time) (examples are Brissonneau \& Ohl, 2010; Christiansen, 2005; Hardie et al., 2010).

Thus, if kept at safe distance from epistemological relativism there are indeed good arguments for bringing humanistic scholarship to the forefront of more general doping research. This is not despite our shared human nature, but because of it. The ability to make analytical generalisations is the reason why we can learn from in-depth interviews with athletes reflecting on their own actions, decisions and attitudes, and why the best (auto)biographies are more informative as regards the characteristics, temptations and deterrents for doping in elite sport than many scientific papers.

\section{Integrating doping research}

Alice Dreger, a professor of clinical medical humanities and bioethics, argues that many of these interstitial problems remain problematic in part because "the science of sport has outpaced the philosophy of sport" (2009, pp. 409-411). Dreger may not completely capture the current state of affairs but she does provide an accurate description for the theoretical and intellectual underpinnings of the current academic conversation about doping. When it comes to problems such as doping that require scientific knowledge, some branches of humanistic sport studies are being left behind.

However, the tendency of some humanity-based scholars to discuss performance-enhancing substances in broad, sweeping generalisations means that their conclusions often fail to have any impact beyond their own discipline. This practice risks leading scholars to create straw men arguments or write philosophical "science fiction." 7 This is likely because their knowledge of their subject matter - doping - trails behind those working empirically and scientifically in the field. The scholars fail to accurately describe what many scientists already know and thus their work is often dismissed. Consequently, scholars in the humanities most likely have not shaped (anti-)doping policy to the extent they could and perhaps should have, and their research remains mostly absent from practical consideration. From a more practical point of view, researchers in the humanities and social sciences have not been especially meticulous in trying to communicate the conclusions of their research to practitioners in the fields, such as international federations and anti-doping organisations. The temptation to engage in arguments internal to their field can distract from their work's applicability. Conversely, results and tests coming out from medical science are more tangible and may be easier to apply and empirically verify. On the other hand, it is equally clear that the science-based approach of testing-based deterrence that has dominated the last 40 years of anti-doping enforcement has not done the job to any level of satisfaction (Kayser \& Broers, 2013; Møller, 2010; Waddington \& Smith, 2009).

The future progress on the doping issue will be the result of connecting and synthesising diverse research to make sense of this multi-faceted problem. First, the study of doping would never have gotten to where it is today without the high-quality research promoted by specialisation in disciplines. These disciplines brought intellectual rigour to doping research when previously myth, emotion and assumption dominated discourse. ${ }^{8}$ Scholars from across the academy's cultures have applied their trades to one of sport's most vexing issues and made great headway.

Discipline-bound research also brings mixed goods. As evidenced in past doping research, silos can become too insular, too trapped in old paradigms, and even mislead the discussion as illustrated by the fashion of social constructivism. This either led to the repeating of assumptions that turned out not to be true or simply made the research in question useless as a tool for coming to an understanding of the pivotal questions. Australian doping scholar Jason Mazanov has suggested a tentative list of topics for social science in drugs in sport, pointing to how doping research transcends individual silos (Mazanov, 2009). No single discipline can fully understand the complex doping phenomenon. Yet cross-disciplinary research, which uses information from other disciplines to inform the questions that researchers ask within their home discipline, require a familiarity with research from different disciplines that often have their own language, methodologies, and professional standards. Even if the establishment of an independent international research centre, receiving arm length funding and doing research on the various issues on drugs in sport would be the ideal way to let researchers from various disciplines collaborate and move forward (Mazanov, 2009), it is probably not realistic at present. If researchers nevertheless make the effort to familiarise themselves with the language, research methods, and advances of different branches of doping research, results from one discipline can be used to strengthen and develop questions of another.

While the doping issue illustrates pitfalls of siloed research, it also shows how cross-disciplinary work can become more viable and successful. One positive way is that cross-disciplinary research

\footnotetext{
${ }^{7}$ Examples of philosophical works with questionable science include Bill Morgan's essay "Athletic Perfection, Performance-Enhancing Drugs, and the Treatment-Enhancement Distinction," W. Miller Brown's article "As American as Apple Pie," and Angela Schneider and Jim Rupert's article "Constructing Winners" (Brown, 2001; Morgan, 2009; Schneider and Rupert, 2009).

${ }^{8}$ See Paul Dimeo's deconstruction of the myth of the death of Arthur Linton in Dimeo (2007) and Verner Møller's deconstruction of the myth of the death of Knud Jensen in Møller (2006). And Bernat Lopez' deconstruction of the myth of EPO and the 17-18 cycling deaths in Holland and Belgium in the late 1980s (López, 2011).
} 
can help us ask new questions and help us see what we take for granted - for instance about anti-doping - in a new light. Bertrand Russell once wrote "Every man, wherever he goes, is encompassed by a cloud of comforting convictions, which move with him like flies on a summer day" (Russell, 2004, p. 16). The constant presence of that mental cloud is the reason why members of a certain research culture or research community seldom reflect on their norms and values, standards for knowledge and methods.

Russell's point is merely that the most obvious, important discoveries can be the ones that are hardest to see and talk about because they appear so familiar. Whether from within the silos of our own discipline or within our own cultural milieu, we often fail to see the world accurately because of our own blind spots, unexamined assumptions and unnoticed limitations. This was proven especially true when it came to the past research on the doping phenomenon. Dominant culture's negative perception of performance enhancing substances such as steroids influence - if not the entire debate - at least where the scholarly discussion starts. One way out of such a situation is to confront possibilities found outside one's own comfortable perspective, the world view provided by one's own discipline. The solution has been evidenced by examples of collaborative research. For example, sociologist Werner Pitsch has used quantitative analysis to investigate normative ethics in doping (Pitsch, 2011), while drug epidemiologist Caleb Banta-Green has used environmental science and sewage analysis to examine drug patterns (Burgard, Banta-Green, \& Field, 2014) and prominent sports medicine scholar Bengt Kayser has used insights from medicine to evaluate drugs policy (Kayser \& Broers, 2013).

Such confrontations are at the heart of doping research. As was clearly evidenced in the early efforts to understand the doping phenomenon, when researchers within a discipline only talk to themselves, they missed opportunities for important discoveries. But cross-disciplinary research on doping can begin anywhere. In fact, humanities-based researchers often move subtly between other humanities-based fields. A sociologist may rely on works of history or a philosopher may draw upon social theory. But extending to other cultures such as the natural or social sciences can prove exceptionally rewarding for those in the humanistic disciplines. Using scientific conclusions about performance enhancing substances to inform more abstract doping policy discussions may entice those particularly interested in for instance the philosophical discussions of doping to consider scientifically driven empirical evidence as required steps to any good research. $p$ Values and empirical data can ground humanistic work often prone to overly theoretical arguments and thereby also sublate the often overly emphasised - but erroneous - distinction between understanding and explanation (c.f. in philosophy Droysen's, and later Dilthey's and in sociology Weber's distinction between verstehen and erklären (Gadamer, 1989)). To put oneself into the shoes of, for instance, athletes that live under the current antidoping regulations, and seek to understand the world from their perspective, does not necessarily involve a social constructivist approach to reality where nothing but the individual's perspective exists.

Hans-Georg Gadamer - the founder of modern hermeneutics - refutes such an epistemological position. As he pointed out, understanding is not centred at one point (e.g. at the individual's subjectivity) but is a movement "from the whole to the part and back to the whole. Our task is to expand the unity of the understood meaning centrifugally." (Gadamer, 1989, p. 291). Hence, to have insights in the larger context of a given phenomenon is prerequisite for knowing the phenomenon itself. Conversely, by including research from less abstract disciplines, readers not typically concerned with humanistic research may be encouraged to find the practical importance in what may appear to outsiders to be abstruse philosophical issues.
And the value of cross-disciplinary research is not unidirectional. The humanities have much to say to the social and natural sciences regarding doping research. The natural sciences, for all their empirical data, cannot provide normative claims about policies or ethics. At the same time, it is not enough for a hypothetical constuctivist humanities scholar to dismiss a scientist's findings about that drug because they perceive that evaluation as a social construction. Such positions would close the dialogue between disciplines rather than open it up. More importantly, in an age where science promises a post-human world where medical and technological breakthroughs will impact sport, the humanities can play a role in ensuring that sporting practices conform to the values the sporting communities agrees upon. Again, such a position is not at odds with our previous critique of the epistemological relativism of social constructivism. Accepting the pursuit of truth as an ideal for one's research does not mean that one has to disregard contingent differences such as the transformation of social values over time, and that these differences are not worth studying. Sport and doping are undeniably social constructions and therefore the political powers regulating them should pay attention to how the cultural values attached to them transforms over time. Humanity based (doping) scholars should certainly aim at saying something truthful about such transformations. With these considerations, it should be clear how a more robust cross-disciplinary discussion might further the sporting world's attempt to address issues related to doping.

\section{Conclusion}

Yet we have the choice to turn to projects of cooperation or engage in conversations with research in various disciplines. Potential collaborative, cross-disciplinary projects or research informed by findings in outside disciplines will likely contribute to solving some vexing problems of our age (Mazanov, 2009). This is because significant breakthroughs often occur when people realise how satellites of information connect to form larger constellations of knowledge. When it comes to solving issues such as obesity or drugs in sports, a single discipline can yield valuable pieces of knowledge. But alone, such insights are only a dot in the sky. When they are connected to other dots, however, they can be used to chart a course towards real solutions. Yet individuals ensconced in their disciplinary silos will struggle to realise those connections as quickly as those with ready accesses to colleagues trained in different fields.

Towards the end of his book on truth and method, Gadamer wrote:

Throughout our investigation it has emerged that the certainty achieved by using scientific methods does not suffice to guarantee truth. This especially applies to the human sciences, but it does not mean that they are less scientific; on the contrary, it justifies the claim to special humane significance that they have always made. The fact that in such knowledge the knower's own being comes into play certainly shows the limits of method, but not of science. Rather, what the tool of method does not achieve must - and really can - be achieved by a discipline of questioning and inquiring, a discipline that guarantees truth (Gadamer, 1989, pp. 490-491).

Good methodology and sound methods are of course necessary to reach that goal. At the same time we must accept how we share a pursuit of truth and how a (sometimes intuitive) knowledge of our shared human nature plays a crucial role in that pursuit. This intuitive knowledge is not to imply unverifiability or assertions without justification; rather, it stakes a claim that accurate insights do not need to follow from a single methodology, whether it is the humanities or the sciences. While physiology and the medical sciences plays a significant role in uncovering how pharmacological 
properties interact with the human body and how certain drugs can perhaps be (indirectly) detected, their meticulous methodologies and designs do not bring us much further towards an understanding of the effects of high performance sport and athletes' decisions regarding drug use in highly competitive environments. Such insights are necessary for establishing any kind of preventive measures and can only be reached by a discipline that - as Gadamer points out - is willing to draw on our knowledge of human nature combined with the ambition of saying something truthfully about the matters at stake.

\section{Financial support}

There was no financial support with this project.

\section{Conflicts of interest}

None declared.

\section{Acknowledgement}

The authors wish to thank the reviewers who provided constructive suggestions for this paper.

\section{References}

Andersen, R. (2014). Has physics made philosophy and religion obsolete? Atlantic, http://www.theatlantic.com/technology/archive/2012/04/has-physics-madephilosophy-and-religion-obsolete/256203/

Beamish, R., \& Ritchie, I. (2006). Fastest, highest, strongest: A critique of highperformance sport. Abingdon, Oxon/New York: Routledge.

Benson, O., \& Stangroom, J. (2006). Why truth matters. London: Continuum.

Booth, D. (2005). The field: Truth and fiction in sport history. London/New York: Routledge.

Brissonneau, C., \& Ohl, F. (2010). The genesis and effect of French anti-doping policies in cycling. In Paper presented at the International Journal of Sport Policy and Politics http://dx.doi.org/10.1080/19406940.2010.488063

British Medical Association. (2002). Drugs in sport: The pressure to perform. London, GBR: BMJ Books.

Brown, W. M. (2001). As American as gatorade and apple pie: Performance enhancing drugs and sports. In W. Morgan, A. Schneider, \& K. Meier (Eds.), Ethics in sport (pp. 142-168). Champaign: Human Kinetics.

Burgard, D., Banta-Green, C., \& Field, J. (2014). Working upstream: How far can you go with sewage-based drug epidemiology? Environmental Science and Technology, 48(3), 1362-1368. http://dx.doi.org/10.1021/es4044648

Carroll, W. (2005). The juice: The real story of baseball's drug problems. Chicago: Ivan R. Dee.

Catlin, D., (1986). 'Summary of the Adverse Effects of Blood Transfusion' March 1, 1986 Correspondence dopage 1986-1988; 205696. (International Olympic Committee Archives, Lausanne, Switzerland).

Christiansen, A. V. (2005). (Not for the money: An insight into modern cycling) Ikke for pengenes skyld: et indblik $i$ moderne cykelsport. Odense: Syddansk Universitetsforlag.

Christiansen, A. V., \& Møller, V.(2007). (Ambitions, drugs and morality: On elite athletes attitudes to sport, doping and fair play) Mål, medicin og moral: om eliteatleters opfattelse af sport, doping og fairplay. Odense: Syddansk Universitetsforlag.

Connor, J. M., \& Mazanov, J. (2009). Would you dope? A general population test of the Goldman dilemma. British Journal of Sports Medicine, 43(11), 871-872.

Connor, J. M., Woolf, J., \& Mazanov, J. (2013). Would they dope? Revisiting the Goldman dilemma. British Journal of Sports Medicine, 47(11), 697-700. http://dx.doi.org/10.1136/bjsports-2012-091826

Diamanti-Kandarakis, E., Konstantiopoulos, P., Papailiou, J., Kandarakis, S., Andreopoulos, A., \& Sykiotis, G. (2005). Erythropoietin abuse and erythropoietin gene doping. Sports Medicine, 35(10), 831-840.

Dimeo, P. (2007). A history of drug use in sport 1876-1976: Beyond good and evil. New York: Routledge.

Dreger, A. (2009, September 13). Science is forcing sports to re-examine their core principles. The New York Times.

Eichner, E. R. (2007). Blood doping: Infusions, eyrthropoietin, and artificial blood. Journal of Sports Medicine, 37(4/5), 389-391.

Evald, J. (2009). Retlige grænser for dopingkontrol. In A. V. Christiansen (Ed.), Kontrolsport - Big brother blandt atleter og tilskuere (pp. 71-88). Odense: Syddansk Universitetsforlag.

Favrholdt, D. (1999). (Philosophical codex: On the foundation of human knowledge) Filosofisk codex: om begrundelsen af den menneskelige erkendelse. Gyldendal.

Fincoeur, B. (2010). La question du dopage à l'aune des étapes de la carrière cycliste. Cahiers de la Sécurité, 11, 72-81.
Gadamer, H.-G. (1989). Truth and method (J. Weinsheimer \& D. G. Marshall (Eds.) Trans. revised).(2nd Rev. ed.). New York: Continuum.

Gergen, K. J. (2000). The saturated self: Dilemmas of identity in contemporary life ([New edition] ed.). New York: Basic Books.

Gleason, J. M., \& Barnum, D. T. (1994). A probabilistic analysis of multiple-drug testing procedures in sports doping control. International Transactions in Operationa Research, 1(4), 395-407.

Gleaves, J. (2011). From science to sport: A cross disciplinary examination of the justification for doping bans (Doctorate of Philosophy). State College, PA: Pennsylvania State University.

Goldman, B., Bush, P. J., \& Klatz, R. (1984). Death in the locker room: Steroids \& sports London: Century Publishing.

Greydanus, D. E., \& Patel, D. R. (2010). Sports doping in the adolescent: The Faustian conundrum of hors de combat. Pediatric Clinics of North America, 57(3), $729-750$.

Hall, M. A. (1996). Feminism and sporting bodies: Essays on theory and practice. Champaign, USA: Human Kinetics Publishers.

Hardie, M., Shilbury, D., Ware, I., \& Bozzi, C. (2010). I wish I was twenty one now. In M. Hardie (Ed.), Beyond doping in the Australian peloton. Australia: Geelong.

Hoberman, J. M. (1992). Mortal engines: The science of performance and the dehumanization of sport. New York: Free Press.

Hume, D. (2003). A treatise of human nature (Dover ed.). Mineola, NY: Dover Publications.

Jaggar, A. M., \& Bordo, S. R. (1992). Gender/body/knowledge: Feminist reconstructions of being and knowing (2nd printing ed.). New Brunswick, NJ: Rutgers University Press.

Kayser, B., \& Broers, B. (2013). Anti-doping policies: Choosing between imperfections. In J. Tolleneer, S. Sterckx, \& P. Bonte (Eds.), Athletic enhancement, human nature and ethics (Vol. 52) (pp. 271-289). Dordrecht, Heidelberg, New York, London: Springer Netherlands.

Kayser, B., Mauron, A., \& Miah, A. (2007). Current anti-doping policy: A critical appraisal. BMC Medical Ethics, 8, 2.

Kierkegaard, S. (1983 (org 1843)). Fear and trembling: Repetition (H. V. Hong \& E. H. Hong, Trans.). Princeton, NJ: Princeton University Press.

Kierkegaard, S. (1991 (org. 1845)). Stages on life's way: Studies by various persons (H. V. Hong \& E. H. Hong, Trans.).(2nd printing, with corrections ed.). Princeton, NJ: Princeton University Press.

Klein, H. (1985, March). Blood transfusions and athletics: Games people play. New England Journal of Medicine, 312, 854-856.

Konner, M. (2002). The tangled wing: Biological constraints on the human spirit (2nd ed.). New York: Henry Holt and Co. Times Books.

Larsen, S. N., \& Pedersen, I. K. (2011). (Sociological encyclopeadia) Sociologisk leksikon. Copenhagen: Hans Reitzel.

López, B. (2011). The invention of a 'drug of mass destruction': Deconstructing the EPO myth. Sport in History, 31(1), 84-109.

Lundby, C., \& Olsen, N. V. (2011). Effects of recombinant human erythropoietin in normal humans. Journal of Physiology, 589(6), 1265-1271.

Magdalinski, T. (2009). Sport, technology and the body - The nature of performance. Milton Park, Abingdon, Oxon: Routledge.

Mazanov, J. (2009). Towards a social science of drugs in sport. Sport in Society, 12(3), $423-430$

Mazanov, J., \& Connor, J. (2010). Rethinking the management of drugs in sport. International Journal of Sport Policy and Politics, 2(1), 49-63. http://dx.doi.org/10.1080/19406941003634032

McNamee, M. J. (2012). The spirit of sport and the medicalisation of antidoping: Empirical and normative ethics. Asian Bioethics Review, 4(4), 374-392. http://dx.doi.org/10.1353/asb.2012.0032

Miah, A., Kayser, B., \& Mauron, A. (2005). Legalization of performance-enhancing drugs. Lancet, 521.

Mirkin, G., \& Hoffman, M. (1978). The sports medicine book. Boston: Little, Brown and Company

Morgan, W. (2009). Athletic perfection, performance-enhancing drugs, and the treatment-enhancement distinction. Journal of the Philosophy of Sport, 36(2), $162-181$

Møller, R. B. (2012). (Sport and ethics. A moral philosophical analysis of sport) Sport og Etik. En moralfilosofisk analyse af sporten (PhD). Aarhus: Aarhus University.

Møller, V. (2006). Knud Enemark Jensen's death during the 1960 Rome olympics: A search for truth? In P. Dimeo (Ed.), Drugs, alcohol and sport. New York: Routledge.

Møller, V. (2008). The doping devil. Copenhagen, Denmark: Books on Demand.

Møller, V. (2010). The ethics of doping and anti-doping: Redeeming the soul of sport? London: Routledge.

Neuberger, E. W. I., Jurkiewicz, M., Moser, D. A., \& Simon, P. (2012). Detection of EPO gene doping in blood. Drug Testing and Analysis, 4(11), 859-869.

Pinker, S. (2002). The blank slate: The modern denial of human nature. New York: Penguin Books.

Pitsch, W. (2011). Caught between mathematics and ethics: Some implications of imperfect doping test procedures. In M. McNamee, \& V. Møller (Eds.), Doping and anti-doping policy in sport (pp. 66-83). London: Routledge.

Popper, K. R. (1992). The logic of scientific discovery. London/New York: Routledge.

Pound, R. W., Ayotte, C., Parkinson, A., Pengilly, A., \& Ryan, A. (2013). Lack of effectiveness of testing programs. Report to WADA executive committee. Montral, Canada: WADA.

Putnam, H. (1992). Renewing philosophy. Cambridge, Mass: Harvard University Press

Reinhold, M., \& Hoberman, J. (2014). The myth of the Nazi steroid. International Journal of Sport History, http://dx.doi.org/10.1080/09523367.2014.884563

Russell, B. (2004). Sceptical essays. London, New York: Routledge. 
Ryba, T. V., \& Wright, H. K. (2010). Sport psychlogy and the cultural turn: Note towards cultural praxis. In T. V. Ryba, R. J. Schinke, \& G. Tenenbaum (Eds.), The cultural turn in sport psychology (p. 422). Morgantown, WV: Fitness Information Tech.

Schneider, A., \& Rupert, J. (2009). Constructing winners: The science and ethics of genetically manipulating athletes. Journal of Philosophy of Sport, 36(2), 182-206.

Snow, C. P. (1993). The two cultures (Canto ed.). London/New York: Cambridge University Press.

Sokal, A. D. (1996). Transgressing the boundaries: Toward a transformative hermeneutics of quantum gravity. Social Text, 46/47, 217-252.

Tamburrini, C. (2006). Are doping sanctions justified? A moral relativistic view. Sport in Society, 9(2), 199-211. http://dx.doi.org/10.1080/17430430500491264

Todd, J., \& Todd, T. (2001). Significant events in the history of drug testing and the olympic movement: 1960-1999. In W. Wilson, \& E. Derse (Eds.), Doping in elite sport. Politics of drugs in the olympic movement (pp. 65-128). Champaign, IL: Human Kinetics.

Todd, T. (1987). Anabolic steroids: The gremlins of sport. Journal of Sport History, 14(1), 87-107.

Tooby, J., \& Cosmides, L. (1995). The psychological foundations of culture. In J. H. Barkow, L. Cosmides, \& J. Tooby (Eds.), The adapted mind: Evolutionary psychology and the generation of culture. New York: Oxford University Press.
World Anti-Doping Agency. (2011). Strategic Plan 2011-2016. http://www wada-ama.org/Documents/About_WADA/Strategy/WADA_Strategic_Plan_20112016_EN.pdf (accessed May 1, 2014)

WADA. (2012). Report of the independent observers. Games of the XXX Olympiad, London. Montreal, Canada: WADA.

Waddington, I., Christiansen, A. V., Gleaves, J., Hoberman, J., \& Møller, V. (2013). Recreational drug use and sport: Time for a WADA rethink? Performance Enhancement \& Health, 2(2), 41-47. http://dx.doi.org/10.1016/j.peh.2013.04.003

Waddington, I., \& Smith, A. (2009). An introduction to drugs in sport: Addicted to winning? (2nd ed.). Abingdon: Routledge.

Widell, P. (2004). (Debating social constructivism) Socialkonstruktivismen under debat. Modtryk.

Wilson, S., Gilbert, K., \& Edwards, A. (2004). The socio-political conservatism associated with doping and high-performance sport: A case study of an athletic squad's perspective. Journal of Exercise Science and Fitness, 2(2), 105-114.

Wittgenstein, L. (1996). Philosophical investigations (3rd ed., repr. ed.). Oxford: Basil Blackwell.

Yesalis, C. E., \& Bahrke, M. S. (2000). Doping among adolescent athletes. Best Practice \& Research Clinical Endocrinology E' Metabolism, 14(1), 25-35. http://dx.doi.org/10.1053/beem.2000.0051 